\title{
Conceptual Evolution of Resilience Capacity and Its Inclusion in PsyCap
}

\author{
Dr. PatirajKumari, Ms. VijayashreeSangwan \\ Professor Department of ManagementStudies,KanyaGurukul,Dehradun. \\ $2^{\text {nd }}$ campus, GKV, Haridwar. \\ Research Scholar Department of Management Studies, KanyaGurukul,Dehradun. \\ $2^{\text {nd }}$ campus, GKV, Haridwar.
}

\begin{abstract}
Human capital in any organisation plays an important role in its development and growth. In today's changing environment human capital can have major contribution not only in sustaining the organisation but in achieving effectiveness and efficiency and thereby making the organisation successful. As such, human capital could be said to possess various capacities such as hope, optimism, efficacy etc. Apart from these capacities, resilience capacity has also been considered as significant specifically during turbulent times that an organisation may face in a fast changing environment. This paper highlights conceptual evolution and constituents of resilience capacity, subsequent inclusion of resilience in psychological capital (PsyCap) and importance of resilience capacity for employees and leaders.

Key Words: Resilience Capacity, Human Capital, Psychological Capital
\end{abstract}

\section{Introduction:}

Development and growth of any organisation to a large extent depends on outlook of its employees apart from their skills. Particularly, the outlook of employees assumes more significance during rough times that an organisation may face in changing business scenario. Resilient employees may prove to be an asset to any organisation. Here, the questions arise -what is resilience or resilience capacity and what makes a person resilient? Whether resilience is related to positive outlook which in turn leads to its inclusion in PsyCap? In the wake of these above mentioned questions, the present paper has the following objectives:

*To find out constituents of resilience capacity.

*To know about conceptual evolution of resilience capacity.

* To investigate the reasons for inclusion of resilience in Psychological Capacities.

Meaning and Definitions of Resilience Capacity:The word 'Resilience' etymologically has its origin in the Latin word 'salire' which means 'to spring up' and 'Resilire' which means 'to spring back'. A resilient object, as defined in the subject Physics, is one that regains its original shape and structure after being stretched. Resilience has been defined by researchers as a capacity, a trait and even a process because resilience can develop over a period of time. Resilience refers to positive outcomes in the presence of adversity and denotes the ability of individuals to bounce back from adversity (Barbara, 2010). Resilience is a human capacity to face, deal with, overcome, learn from, and be strengthened by or even transformed by experiences of adversity (Grotberg, 2001).

According to Webster's new twentieth century dictionary of the English language, "Resilience is the act of rebounding or springing back after being stretched or pressed and recovering strength, spirit and good humor."According toMasten (1994), "The term resilience has a connotation of a personality trait."

According to Fraser, Richman\&Galinsky(1999) "The term 'resilience' is reserved for unpredicted or markedly successful adaptations to negative life events, trauma, stress and other forms of risk." In addition to this they state that "If we can understand what helps some people to function well in the context of high adversity, we may be able to incorporate the knowledge into new practice strategies".

Tugade \& Fredrickson (2004) mentioned that in the face of loss, hardship or adversity, ability to effective coping and adaptation is psychological resilience. Furthermore, a resilience training programme providerRobertson Cooper Ltd (2013) define- "Personal resilience is the capacity to maintain well-being and work performance under pressure, including being able to bounce-back from setbacks effectively. Our natural resilience is a combination of personal characteristics and learned skills - but most importantly the quality can always be developed whatever an individual's starting point; and in times of change and growth it's becoming increasingly important for individual and business performance" 
In the absence of resilience- demands, posed by work life and everyday lifewhich includes relationships, family, home finances and health issues in an increasingly complex and demanding world, cause people to suffer from stress which results in anxiety, panic attacks and depression as well as frequent cold and cough, high blood pressure and even heart disease (Green \&Humphrey, 2012). Stress is one of the most researched subjects as it affects the behavior of the employee at work. As defined byChauhan (2005) "Stress is a psychophysiological arousal response occurring in the body as a result of a stimulus which becomes a stressor by virtue of the cognitive interpretation of the individual" whether we think of stress or distress, resilience capacity is something that contributes to subside the effects of any such construct which overwhelms an individual or affects him negatively.

Resilience capacity at the individual level encompasses skills, competence, traits and positive cognition, altogether these can be called psychological factors which enable an individual to cope with difficult situations and adapt positively.An individual's personal characteristics, which include his ability to comprehend and respond (cognitiveabilities) to demands, adverse situations or trials along with family and social support, determine his level of resilience. Cognition or a positive cognition could prove to be one of the most supporting protective factors during difficult times. According toMorrow \& Chui (2012), "cognitive resilience is certainly a resource for autonomy through which to maintain and nurture

health, social networks, and behavioral repertoires that are rich and satisfying."Also, they mentioned personal agency (extent to which an individual can have control on situation or events) is the focal point of resilience process. Personal agency contributes to the adaptive behaviours of individuals. Resilient individuals have optimistic, zestful, and energetic approach to life, are curious and open to new experiences and are characterized by high positive emotionality. Furthermore, highly resilient people proactively cultivate their positiveemotionality strategically eliciting positive emotions through the use of humour, relaxation techniques and optimistic thinking (Tugade and Fredrickson, 2004).According to Benard (1991), researchers have used several other terms for resilience such as 'invulnerable', 'stress-resistant', 'hardy', 'ego-resilient', and 'invincible'.

Researchers have studied the sources of the construct resiliencecapacity at three levels and these levels are: individual, family and community or society. Different factors belonging to these three domains together create resilience capacity. Among these three- individual level seems to be the most important as this indicates towards personality traits, skills and competence of an individual. On the basis of these possessions an individual interacts with family and society during a lengthy span of time. Family and community provide support to an individual. Traits collectively with skills make an individual resilient and resilient individual with his accomplishments gain more skills and competence. For example, hardiness or toughness is one such important trait that helps enhance the level of resilience.

Maddiand Deborah (2005) mentioned that "According to the longitudinal study of Illinois Bell Telephone, resilient group of employees had a hardy attitude of commitment, control, and challenge. Further, some of the resilient people not only survive, but actually thrive. They find ways to turn stressfulcircumstances into opportunities for personal growth.". Here in the following figure, it can be observed that hardiness is a trait that involves individual personal characteristics which enable him/her to cope with the difficult situations, get transformed positively by learning from them and to have social interactions. This hardy attitude makes him/her resilient to face adversities. Further, overcoming difficulties and accomplishments in spite of stressful situations enhances level of resilience and resiliency contributes to the enhancement of hardiness.

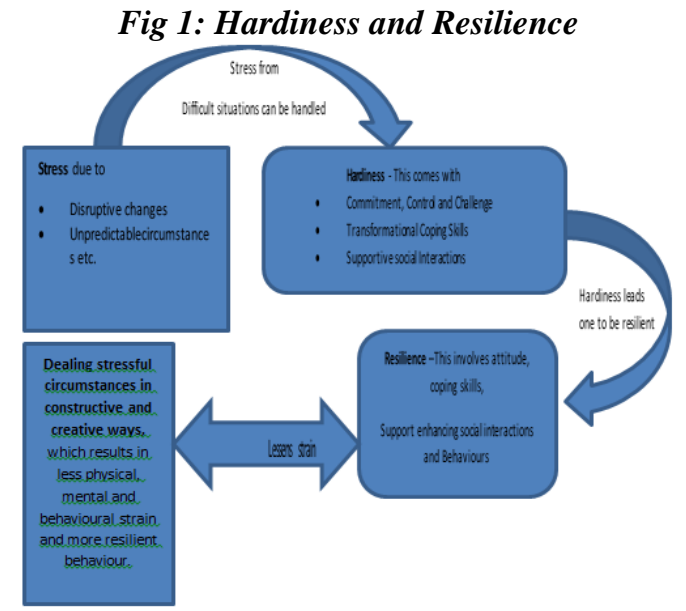

Based on the interpretation of the information available in Maddi, S. R., and Deborah M. K.(2005). Resilience 
at work.

Conceptual model of resilienceincludestwo kinds of factors-risk factors(factors that increase vulnerability and victimise) and protective factors, which are present in any context wherein level of resilience of an individual is to be studied.

As mentioned by Lee et al. (2013) in their meta-analysis - resilience, which is a developmental process, refers to "the personal qualities and skills that allowfor an individual's healthy and successfulfunctioning oradaptation withinthecontext of significant adversity or a disruptive life event". Age and gender according to them are two demographic variables connected to the level of resilience In addition, the two categoriesof psychological factors associated with resilience are: (a)riskfactors and (b) protective factors. These can be depicted as under:

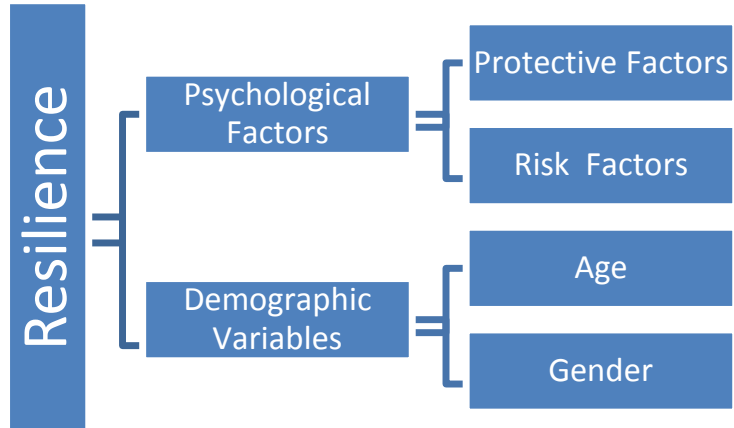

Fig 2: Categories of Resilience

Based on the interpretation of the information available in Lee et al. (2013). Resilience: A Meta-Analytic Approach. Journal of Counseling and Development.

Protective factors existing in a situation, which has risk factors, build resilience. As Thomas (2011) mentioned that theoretically, the more protective factors one has, the more likely he/she is to be resilient. Still, she added, one or two protective factors can be supportive enough to make a person resilient to face adversity and difficulties. This is resilience capacity of an individual, which in the literature has been considered to be a determinant of success.Protective factors by researchers have been organized in three categories: 1) Personal characteristics of an individual (inner strength), 2) Family and 3) Community( external support) (Werner,1989; Infante\&Lamond, 2003;Thomas, 2011).Individual interaction with social resources enable positive adaptation in spite of existence of adverse conditions(Infante\& Lamond,2003). In the figure (3), it has been depicted that resilience capacity is a result of individual factors(sense of purpose, autonomy, social competence, and problem solving skills),family characteristics(care and support, encouragement, high expectations, and sense of responsibility),environmental influences( social support from family members, friends, relatives and community) as per the study of Benard(1991).An 'arrow shape' joining three rectangular shapes depicting the above mentioned factors shows their continuous interaction. "Resilience is a dynamic process whereby individual personality and environmental influences interact in reciprocity and transactional relationship" (Benard, 1991).This is imperative to state here that the most important factor of resiliency according to researchers is -individual or personal traits such as the capacity to manage strong feelings, good problem solving skills, positive self-concepts, high intelligence and self-confidence,capacity to make realistic plans and carry them out,ability to cope with stress effectively and in a healthy manner,spirituality, helpful nature,finding positive meaning in negative situations, self-esteem, self-efficacy etc. Secondly, it is the family, which supports emotionally, morally and financially and the third factor is social support. Personal traits of an individual are a must as they are fundamental to the ability to interact with others and to adapt positively during tough times. Positive coping strategies, which have been divided into three categories as per Keltner\& Walker (2003), such as protecting(strengthen oneself from emotional pain), modifying (learning to deal with physical, emotional, and social facets of a situation), and boosting ( enhancing courage and elevating selfesteem, also contribute to positive adaptation of a risky or difficult situation. 
Fig 3: Division of Protective factors and interaction among them

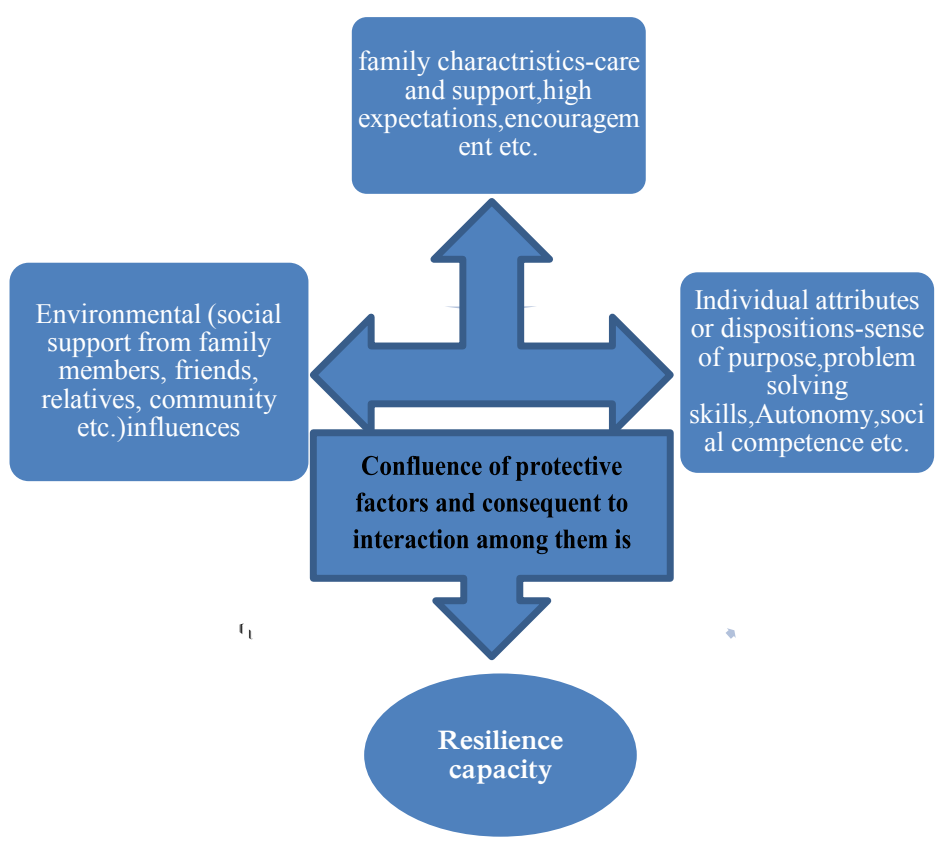

Based on the interpretation of the information available in Benard, B. (1991). Fostering Resiliency in Kids: Protective Factors in the Family, School, and Community.

Thus, resilience is about having protective or promotional factors such as personality traits, skills, competence and support from others in the presence of challenges, difficulties, demands and pressures so as to overcome them.

Correlates of Resilience: Davis (1999) suggests that there are several characteristics which are correlates (which depends on or affects) of resilience and these can be consequent to being successful in a situation. These factors are mentioned in the figure given below, and if compared to those mentioned in the fig 3: (Division of protective factors) and pondered over then we can draw an inference that physical competence, spiritualcompetence, moralcompetence, emotional and cognitivecompetence will fall under the category of individual factors and social and relational competence though an individual factor, can be considered to be under the category of environmental influences due to relationships and interaction with others.

Fig 4: Correlates of Resilience

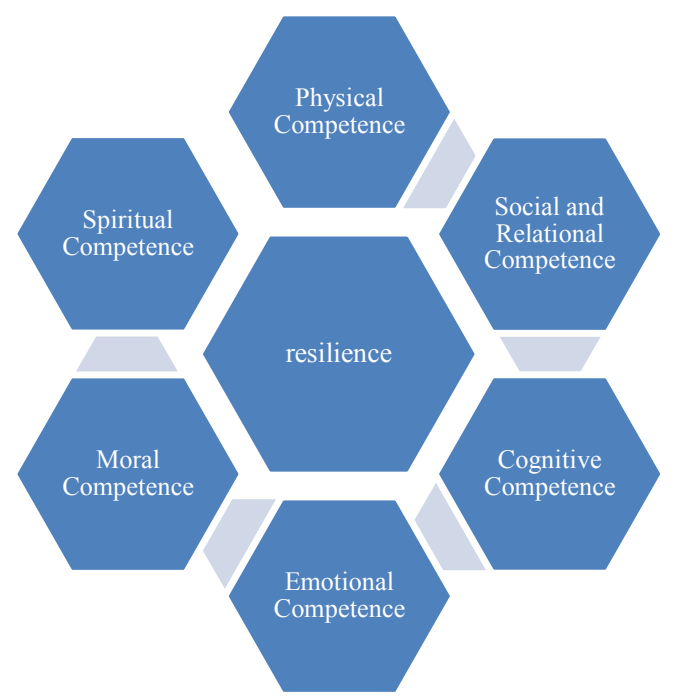



and research-based programs.

\section{Important theories and terms related to resilience:}

Blocks' Ego resilience:Block (2002, p. 185)explains this theory of resilience wherein he describes that expressions and containment of impulse behaviour are decided by complex ego structures, which determines invulnerable adaptation modes and limitations in a personality system. An individual can evolve ego resiliency of perception and of behaviour. The ER construct envelopsvarious personality attributes such as active and meaningful engagement with the world, a positive and energetic approach to life, confidence, autonomy, competence, a sense of mastery within multiple life domains, perceptiveness, insight, the capacity for warm and open relationships, good interpersonal skills, social poise,secure attachment and personality consistency over time, delay of gratification, friendship understanding and moral judgment (Davis, 1999).

Society to Cells Resilience: As proposed by Szanton, Sarah L.; Gill, Jessica M. et al.(2010), resilience is a process which every individual passes through as his/her life progresses and this can be observed through "resistance, recovery, or rebound processes". This theory explains the following factors as contributors in resilience process:

1) Inborn resilient potential along with the changes which occur due to interaction with society (Natural Ecosystems, Safety in Environment, Education and Career Opportunities, genders being resilient in different capacities),

2) Community (Institutions, Social Support, Social Trust and Civic Participation,Personmade physical structures and infrastructures, Diversity),

3) Family (Developmental Opportunities, Sense of Safety and Security),

4) Individual (View of Self, View of World, Coping Strategies, Spirituality, Race)

5) Psychological (Neurochemical Activity, Hormone Balance, Glucose Regulation, Inflammation),

6) Physiological (Genetic Inheritance, Epigenetics, DNA Repair, Oxidative Stress, Mitochondrial Function), and cellular factors and reaction of all these factors to challenges, which can be external (e.g., a traumatic event) or internal (e.g., disease processes).

Cognitive Resilience:This term includes"negative effects of setbacks and associated stress on cognitive function or performance", and a number of factors such as "locus of control, cognitive appraisal, learning, social support systems, experiences, motivation, efforts and other individual characteristics" (Staal et al., 2008)

Emotional Resilience:According to Cloyed (2013)“the ability to maintain, or recover, good feeling about oneself independent of one's environment."People with emotional resilience have emotional control and staying persistent, confident, and organized, they follow their goals, solve problems and get along well with others (Bernard, 2003).

Educational Resilience: is "the heightened likelihood of success in school and other life accomplishments despite environmental adversities brought about by early traits, conditions, and experiences" (Wang, Haertel, and Walberg, 1994). This term may have relevance for managerial professions, therefore has been mentioned here.

\section{Evolution of the Concept:}

The history of Resilience in human beings rests in research studies on children, which is an ingredient to developmental psychology. Although Norman Garmezy has been considered to be a "peerless pioneer in the study of competence and resilience" who conducted a longitudinal study on children starting from 1941(Deveson, 2003), the study of resilience is said to have begun with the research project, conducted by Emmy Werner and her associates. "the landmark research, or the first study credited with digging into this topic, is a longitudinal study conducted by Emmy Werner" (Thomas, 2011).In her answer to the question on 'concept of resilience' in her interview, Werner revealed that the word occurred to her first while talking to her son (who is an engineer) about the children under study as she thought "these people may bend but they do not break" (www.readperiodicals.com, 2012).Furthermore, it would be appropriate to mention here that Masten et al.(2012), who have been close associate of Norman Garmezy, have stated Emmy Werner as 'another pioneer'. According to Masten and Tellegen (2012) the Minnesota Risk Studies on children conducted by Garmezy and Colleagues focused on understanding individual differences in adaptation in the presence of adversity, positive adaptation in the cohort of children, manifestation of competence in the children at risk due to biological and environmental factors and such children were termed as 'invulnerable' and their competence to survive and thrive in an environment salient with stressful life events was termed as 'stress- resistance'. The ideas poured from the fields of developmental psychology, clinical psychology, behaviour genetics, personality, and 
psychiatry. Over a span of time the concept of resilience was developed along with the inclusion of system theory and they defined resilience in 1990's as "the process of, capacity for, or outcomes of successful adaptation despite challenging and threatening circumstances." And by the year 2011, the definition of resilience, according to them, was "the capacity of a dynamic system to withstand or recover fromsignificant threats to its stability, viability or development". And with this definition of resilience 'Society- to- Cell theory' of resilience, seems to be supported as further Masten\&Tellegen (2012) specified that the recent definition has the 'advantage of scalability across system levels (cellular to neural to whole organism to family to larger social and cultural systems) as well as applicability to different field of study, such as ecology'. However, the conceptual model of resilience describes only protective and risk factors existing in the context under any study to be conducted.In resilience literature, the ecological-transactional model of human development has been described, as per this model transactional interchanges, between individual and family, individual and neibourhood within a context over a period of time, shape positive adaptation. Theoretical acceptance of this has formed the ways for researchers in identification of 'protective factors' along with identification of risk factors. Protective factors have been categorised as -individual attributes or dispositions, family characteristics and environmental factors (Bernard, 1991; Luther, Cicchetti,\& Becker, 2000).Thus, resilience capacity can be said to be the outcome of protective factors and underlying process wherein these factors interact with each other in a particular context so as to enable an individual to survive and thrive despite of circumstances full of difficulties and adversity.

According to Thomas (2011) the research on children that was started in 1954 on the island of KauaiHawaii covered various factors such as impact of prenatal stress, physical and emotional status of the mothers, material, intellectual, and emotional aspects of families, risks and vulnerability of children due to poverty. Moreover, the researchers followed these children through adulthood and continued the research having focus on mental health problems, antisocial behaviour and this is during this time of their study when they found that there are several children, despite having such unfavourable life situations, growing and coping with their problems so positively.This provided a new dimension to the researchers to study and they changed focus of their research from risk and vulnerability to resilience capacity, searching for the roots of resilience through their previous researches. This research was collectively conducted by psychologists, paediatricians and public health workers. This entire longitudinal research has been documented in several books such as The Children of Kauai (Werner, Bierman \& French, 1971), Kauai's Children Come of Age, (Werner \& Smith, 1977), Vulnerable but Invincible, (Werner \& Smith, 1982), Overcoming the Odds: High Risk Children from Birth to Adulthood(Werner \& Smith, 1992), Journeys from Childhood to Midlife (Werner \& Smith, 2001).About resilience, Werner, \& Smith (1992) has stated that it is 'inborn capacity for self-righting'.

The children who did not show any destructive behaviour were called resilient. Both risk factors and protective factors were studied by the researchers. The protective factors are those which enhance one's ability to cope with the stress and adversity. As studied in The International Resilience Project conducted by Bernard Van Leer Foundation and Grotberg(1995),also mentioned by Grotberg(2003),describes resilience as a universal capacity by which a person, group or community can prevent, minimize or overcome the effects of adversity. It is resilience that strengthens a child to face stressors, without resilience experiences with adversity may crush a child. As per this study, there are several risk factors within the family and outside such as divorce or separation; illnessofa parent or sibling; poverty; moving; accident causing personalinjury; abuse, sui cide;remarriage, homelessness;poorhealth and hospitalization; firescausingpersonal injury; forced repatriation of family; disabledfamilymember; parents' loss of job or income. outside the Family:Robberies; war; fire; earthq uake; flood; car accident; adverse economic conditions; illegal refugee status; migrant status;propertydamage fr om storms, floods, cold; political detention; famine;

unstable government; drought, terrorism, as well as drugs, violencebullying, road rage, singleparent familiesliving in pove rty, discrimination, racism, and mental health problems. The protective factors have been divided by Grotberg (1995) into three categories:I Have (External support), I Am (inner qualities), and I Can (Interpersonal and problem solving skills).

Description of some researches on resilience Capacity: Several researchers have conducted researches and described resilience capacity in terms of protective factors one possesses in the difficult and adverse context: in line with this statement various researches are mentioned below:

Masten (1994) described various protective factors such as effective parenting; good intellectual skills; selfefficacy, self-worth and hopefulness; areas of talent or accomplishment valued by self and others;good schools and other community assets; socioeconomic advantages; faith in religion; connection to competent people; and good fortune.

Richardson (2002) has described resilience dividing it in three waves: first wave envelops resilience qualities such as optimism, self- regulation, acceptance, orientation toward solutions, responsibility, caring attitude towards family and friends, ability to set realistic goals etc. Second wave covers biopsychological homeostasis or equilibrium point that an individual would want to return to after having experienced difficulties; homeostasis 
could be said to be a result of an individual's adjustment to a set of circumstances. Third wave describes resilience as an inner strength that drives or motivates an individual towards self- actualisation.

Ozbayet el (2007) mentioned that there exists a strong relationship between good social support and superior mental and physical health. A further, high social support protects against impact of mental and physical illness and social support through effects on psychosocial and neurobiological factors seems to moderate genetic and environmental vulnerabilities.

Carbonell and Stashwick( 2002) mentioned that as opposed to childhood risk factors for major depression, significant protective factors included family cohesion, positive self-appraisals and good interpersonal relations.

Luther, Cicchetti and Becker (2000) mentioned in their critical review of the construct resilience that the three sets of factors: 1.attributes of the children themselves, 2.aspects of their family and 3. Characteristics of their wider social environment are involved in the development of resilience. According to them, positive adaptation in spite of the presence of adverse situations involves a developmental progression as new strengths or vulnerabilities come with changing situations. Much research on resilience is based on the above mentioned triarchic framework. Resilience as these researchers mention "is not necessarily a transient or ephemeral phenomenon" or "not a static state".

As mentioned by Davis (1999),individual clinicians for the treatment broadened their focus including not just illness and diseases but also the factors involved in the development of competence, health and resilience. $\mathrm{He}$ mentioned increased rates of divorce, homelessness, and poverty among young families with children, more concern about births to single parents, teenage pregnancy, child abuse, and domestic violence, and increase in problems such as suicide, substance abuse, violence among children and adolescentsas risk factors. Davis has mentioned some important points related to resilience and these are: 1. 'resilience may change overtime and in different domains', 2.resilience needs to be judged both in terms of internalising and externalising difficulties. Different variables related to resilience are: Physical Competence

( Good health and temperament, good prenatal care), Social and Relational Competence(Secure parental attachment and basic trust, ability to reflect upon the mental states of oneself and others, ability and opportunity to have helpful people, ability to befriend with people and having a few stable friends, positive relationships with peer group, interpersonal awareness or role-taking abilities, empathy), Cognitive Competence(Average to above average intelligence quotient and emotional intelligence quotient, ability to communicate, planning and organising skills, good problem-solving abilities, positive future expectations, internal locus of control, assertiveness, optimism),Emotional Competence( Emotional regulation, ability to delay gratification, realistically high self-esteem, sense of autonomy, ability to think and work creativity, and a sense of humor),Moral Competence(ability and opportunity to contribute),Spiritual Competence(Faith in life, and having an understanding of meaningfulness in positive actions).

Infante and Lamond (2003, p. 162) have mentioned Personal characteristics, Social and problem solving skills (interaction with external resources), deep cultural attachment and strong family relationships as main factors constructing resilience as per their study, which they conducted on American immigrants -'Latino population'. According to them, resilience and its categories-the inner strength, the external support from family and community, are strengthened by the interaction of the individual with social resources; which facilitates a positive adaptation in spite of the difficult and adverse conditions. In their Latinos' case, these researchers considered the country of origin, socio-economic status, and experiences of discrimination etc. as adverse situations and found out resilience factors; which helped Latinos adapt to new culture and develop biculturism. These resilience factors included: Personal characteristics such as a strong sense of responsibility, optimism, autonomy, and the confidence of creating a positive change, motivation to achieve a higher economic and they could in their country of origin, motivations to provide hope and good opportunities to children ,favourable history of positive adaptation and success of other immigrants, optimism, responsibility, and belief in the possibility of change in combination with external support, helped the individual acquire the necessary skills required to adjust to the environment of a new country.Social and problem solving skills (interaction with external resources)such as communication skills: which include expression of feelings, communicating expectations, capacity to reach out, find available resources and establish strong relationship with service providers.

High value of culture of origin and its traditionsalong with acceptance of new values and expectations(deep cultural attachment), keeping a sense of family and regards for their roots (strong family relationships) found to be key factors to have constructed resilience in Latino community. Whitbeck, Hoyt, Stubbon\&Lafromboise (2001) found in interviews with 196 American Indian children that the degree to which children were embedded in traditional culture positively affected their school performance. The study provided empirical evidence that 'Enculturation is a resiliency factor in the development of American Indian children. Graham (2001) in his study 
on American Indian children investigated the role of spirituality in promoting resilience which in turn supported school based competence.

According to Newman (2003, p. 234) resilience is not something extraordinary and usually people show resilience (process of adapting well) in the face of difficulties, adversity, trauma, tragedy, threats and stressors which include family, relationship, workplace and financial problems. Resilience according to him includes behaviours, thoughts and actions which can be learned and developed over a period of time. A further, he mentions the capacity to make realistic plans and to carry them out, self- confidence and a positive view of oneself, communication and problem solving skills, the capacity to manage strong feelings and impulses, having caring and supportive relationshipsare factors that contribute to resilience. In addition to this, he suggests a number of strategies to build resilience. These are: maintaining good relationships and accepting support from them, change in interpretation and response to problems, acceptance of change as a part of living, development of achievable goals, taking decisive actions, nurturing a positive view of oneself, keeping a long term perspective, maintaining hopeful outlook etc.

Keltner\& Walker (2003) described a conceptual model of resilience in their study on children with special health care needs, wherein they have mentioned the need of such child and their family to adjust to the limitations, which arise due to chronic diseases. Risk factors involved depression, anxiety, and stress etc. protective factors included (1)skills, favourable behaviour with children in schools, and three other factors such as dispositional attributes of the individual- activity level and sociability, average intelligence good communication skills and internal locus of control, (2) family that provides emotional support in times of stress (3) external support systems, whether in school,work, or church, that reward the individual's competencies and determination and provide a belief system by which to live.

Al-Naserand Sandman (2000) mentionedthat the quality of resilience shows in the way people deal with changes that occur in life and actions they take in response to changing situations. They describe resilience as a quality which is influenced by experiences, during childhood, during teenage and adolescence and also by the circumstances in adult life.

According to Morrow \& Chui (2012) the central point of the resilience process is about having a sense of personal agency which is supported by a number of individual factors such as health, cognitive and motivation, social factors such as social support, sociocultural factors, such as social equity, education system and structure that nurture sustained intellectual engagement.These factors enhance an individual's capacity for positive adaptation.

Researchers in resilience have focused on psycho social, moral, spiritual and cognitive components of human development when describing theoretical models (Sharksnas, 2002).

According to Lee et al. (2013) there exists a positive relationship between protective factors (such as satisfaction with life, optimism, positive affect, self-efficacy, self-esteem, and social support) and resilience.

Resilience- whether it is defined as a process (Benard,1996), innate resilience (Richardson, 2002) or capacity (Masten,1990), which safeguards an individual during the times of adversities; researchers have divided the protective factors in three categories mostly-Individual/personal characteristics, support from the family, and support from the society, Regardless of the changes in Risk factors as per the context; one protective factor or a combination of them, enables one to deal with the situation.

\section{Concept of Positive Psychology and Psychological Capital: Inclusion of Resilience in PsyCap}

Research on resilience before 1990s included studies on factors which caused vulnerability and those factors existing in the situation which provided protection against vulnerability or risks. Researches conducted after 1990s emphasized on finding out about protective factors and interaction among those factors, along with mechanism that enabled that interaction so as to understand about the capacity that enabled risk population supersede risk factors (Thomas, 2011; Infante\&Lamond, 2003). As such the researchers turned their focus from the treatment of weakness, illnesses and risks (psychopathology) to identification of positive/protective/promotional factors that strengthen an individual make him survive and thrive in an adverse context; Psychopathology could be understood in relation to normative adaptation and development, in the same way, developmental psychopathologists recognised the importance of research on competence and resilience as well as studies of maladaptation and the necessity to study processes and pathways to success as well as those leading to maladaptive outcomes(Masten\&Tellegen,2012).Consequently, it can be said on the basis of review of literature that as a result of these researches and also with some personal experiences of psychologists such as Seligman, the concept of positive psychology came into existence. Positive Psychology researches were led by Martin Seligman (Luthans, 2002a). According to Seligman (2000), the former president of American Psychological Association, the aim of positive psychology is to start to bring change in the focus of psychology from treating worst things in life to building positive qualities. As such Psychology is not limited to the study of pathology, weakness and damage; it envelops the study of strength and virtue. Also, treatment accommodates not just handling weaknesses and problems but nurturing virtues, strengths and positivity. The concept of 
positive psychology contains roots of Positive Organisational Behaviour, which is about application of Psychological Capital (PsyCap-Hope, Optimism, Resilience and Efficacy) at workplace. The terms positive organisational behaviour and psychological capital have been coined by Prof. Fred Luthans on the basis of emergence of positive psychology wherein researches started focusing more on strengths instead of weakness, resilience instead of vulnerability and development of wellness, prosperity, and a good life instead of pathological treatment.

Luthans, Youssef, \&Avolio (2007) defined PsyCap as “ Psychological Capital is an individual's positive psychological state of development and is characterised by:1) having confidence (Self -efficacy) to take on and put in the necessary efforts to succeed at challenging tasks;2) making a positive attribution (optimism) about succeeding now and in the future;3) persevering toward goals and when necessary redirecting path to goals (hope) in order to succeed; and when beset by problems and adversity, sustaining and bouncing back or even beyond (resilience) to attach success."

Although resilience was started to be studied in children; the construct has been added in Positive Organisational Behaviour due to its relevance at the workplace. As defined by Luthans (2002a), resilience is "the developable capacity to rebound or bounce back from adversity, conflict, and failure or even positive events, progress, and increased responsibility."

Positive Organisational Behaviour according to Luthans (2002b) is "the study and application of positively oriented human resources strength and psychological capacities that can be measured, developed and effectively managed for performance improvement in today's workplace." POB constructs as Luthans describes are more state -like (less fixed and can be developed) not trait-like (fixed) such as attitudinal and motivational variables. POB applies to Leader/manager development and human resource development; this is directly applicable to leadership development through organised programs and /or on the job (career assignment or mentorship).The same is true for HR development which can be administered either through formal training programs or through the employees' leaders on the job (coaching).Initially, five constructs such as selfefficacy,hope,optimism,subjective well-being and emotional intelligence were included in POB.

Luthans (2002) mentioned in his invited essay about taking a proactive positive behavioural approach in today's environment, which he mentioned is featured with economic uncertainty, increased geographical unrest, increased competition, and advanced technology. Also, he describes that relative attention in organisational behaviour has been on negative(stress, burnout, resistance to change, deficiencies, problems and dysfunction of managers/employees) instead of positive affectivity(eustress, acceptance to change ,strengths and psychological capital) for development and improvement of performance.

Luthans and Youssef (2007b) mentioned that focus should be on building on strength not on just treating weaknesses. However, positive perspective is also not that simple, and risk free as a positivity approach may promote a more benevolent view of human beings than it should be. As such overconfidence, false hope and unrealistic optimism may result into poor performance, poor allocation of resources and energies in ineffective goals and avoidance of responsibility respectively. In spite of this, PsyCap (Hope, Optimism, Resilience and Efficacy) is state like that is malleable, open to change and development and due to these developmental characteristics the psychological capacities are relevant in today's fast -paced and unpredictable workplace. Productive work has been found to be related to physical well- being which can be attained through adequate work life balance, preventive health care, diet and exercise, and happiness and psychological well- being.

Furthermore, mentioning importance of resilience in the making of a leader, Patterson, Goens\& Reed (2009) have described three broad sets of skills that are required to be resilient: 1.Resilient thinking skills (optimism, high expectations, maintenance of positive outlook with a sense of constraints that exist in reality), 2. resilience capacity building which included accumulation of experiences, personal values (ethical values, educational values and core values specific to programs in organisations as these affect actions), personal efficacy(confidence in one's ability to reason and make decisions with adherence to core principles values and , assuming responsibility for personal actions, helping others develop self-efficacy, leadership competence in serving others ), personal well-being(physical, emotional and spiritual well-being) and personal support base(support of family, friends, colleagues and mentors),3.resilient action skills( showing perseverance, courage, adaptability and personal responsibility in actions).

\section{Conclusion:}

When we converse about resilient individuals or resilience capacity in human beings-we refer to their ability to bounce back from any stressful, adverse, and traumatic states posing challenges, which could be arising from any part of life-professional and/or personal. Positive behaviour and growth of an individual, in the presence of crisis, challenges, stress and in any adverse life situations, are a result of his/her resilience capacity.Capacity for resilience envelops a range of factors at the individual level, family level and at the level 
of society, and strengthens an individual to face not only day to day hassles, stresses and difficulties but also works as a cushion against adversities, strain and trauma.

There may be no consensus among researchers on the definition of resilience, nonetheless, resilience, as described in different definitions, has one similarity and that is- if there is a situation featured with risks, adversities or negative events in an individual's life, then these are protective factors existing in that situation which capacitates him to rise above.

Therefore, Resilience capacity, trait or process can be defined as a confluence wherein protective factors ( which enhance adaptation) such as individual traits, skills and competence, positive emotions, family support and social support interact with each other in such a pattern that enables an individual not only to face a situation but ensures his survival and success also in spite of the presence of risk factors (which enhance maladaptation) such as difficult and stressful life events, trauma and adversities in that situation or context.Resilience capacity has its due relevance as it underpins positivity and a sound system whereby both employees and organisations can thrive in a challenging environment.

\section{Suggestions for Future Research}

Resilience Capacity can be studied further in association with organisational effectiveness and efficiency, employee productivity, organisational citizenship behaviour, counterproductive work behaviour, task performance, work life balance, organisational culture and commitment. Organisations can identify protective factors for their workforce against risk factors arising out of changes in environment and lay down such policies and programs that reduce absenteeism, under performance, and attrition rate etc. after getting to know about what makes their employees resilient and efficient through researches on this variable.

\section{References:}

[1] Al-Naser, F., \& Sandman, M. M. 2000. Evaluating Resiliency Patterns Using the ER89: A Case Study from Kuwait. Social Behavior and Personality: An International Journal,Volume 28,Issue5, pp 505-514. Retrieved from http://www.questia.com

[2] Barbara, R., Lisa, P., Karen, A. 2010. Resilience in aging: concepts, research, and outcomes. New York: Springer.

[3] Benard, Bonnie .2002. Application of Resilience: Possibilities and Promise, Resilience and DevelopmentLongitudinal Research in the Social and Behavioural Sciences: An Interdisciplinary Series 2002, pp 269-277,Springer.com/chapter/10.1007/0-306-47167$1 \_14$

[4] Benard, B. 1991. Fostering Resiliency in Kids: Protective Factors in the Family, School, and Community. Portland, OR: Western Center for Drug-Free Schools and Communities.

[5] Benard, B. 1996. Fostering Resilience in Children. Retrieved on February 23, 2010 from http://crahd.phi.org/papers/Fostering.pdf.

[6] Bernard, M.E. 2013.Emotional Resilience: Implications for You can do it! Education Theory and Practice. Retrieved from http://www.youcandoiteducation.com/reflectionsonemotional_files/ReflectionsOnEmotional.pdf.

[7] Carbonell, D.M. 2002. Adolescent Protective Factors Promoting Resilience in Young Adults at risk for Depression, Child and Adolescent Social Work Journal, Vol. 19, No. 5,pp 393-410

[8] Chauhan, D., and Chauhan, S.P.2005.Stress: Can it be a Motivating Force for realising one's Potential. Indian Journal of Industrial Research, volume 40,No.3,pp 410-419.

[9] Cloyed, T.2013.Building Emotional Resilience: Finding and Calming Negative Self Beliefs to Decrease Personal Distress and Become Stronger.Retrieved fromhttp://www.tomcloyd.com/lib_iudb06072-emotional-resilience.html.

[10] Davis, N.J. 1999. Resilience: Status of research and research-based programs. Working paper, Center for Mental Health Services, Substance Abuse and Mental Health Services Administration, U.S. Department of Health and Human Services; Rockville, MD. Retrieved July 13, 2011 from: http://resilnet.uiuc.edu/library.html

[11] Deveson, A. 2003. Resilience, Allen \& Unwin, National library of Australia

[12] Fraser, M, Richman, J, \&Galinsky, M. 1999. Risk, protection, and resilience: Towards a conceptual framework for social work practice. Social Work Research, Volume23 Issue 3, pp 131-143.

[13] Graham, 2001. Resilience among American Indian Youth: First Nations Youth Resilience Study." Ph.D. diss., University of Minnesota,

[14] Green, A., and Humphrey, J.2012. Coaching for resilience: a practical guide to using positive psychology. New Delhi: Replika Press Pvt Ltd.

[15] Grotberg, E. 1995. A Guide to Promoting Resilience in Children: Strengthening the Human Spirit,The International Resilience Project,Bernard Van Leer Foundation, Retrieved from http://resilnet.uiuc.edu/library/grotb95b.html

[16] Grotberg, E. 2001.Resilience programs for children in disaster, Ambulatory Child Health, Blackwell Science Ltd. Volume 7, Issue 2,pages 75-83, DOI: $10.1046 / j .1467-0658.2001 .00114 . x$

[17] Grotberg, E. H. (Ed.). 2003. Resilience for today: gaining strength from adversity. Westport, CT: Praeger, Retrieved from http://www.questia.com

[18] Infante, F., and Lamond, A.2003. Ch. 7. Resilience and Biculturalism: The Latino Experience in the United States, pp.161-188, from Grotberg, E. H. (Ed.). (2003). Resilience for Today: Gaining Strength from Adversity. Westport, CT: Praeger. Retrieved from http://www.questia.com

[19] Keltner, B., \& Walker, L. 2003. Resilience for those needing health care. In E. H. Grotberg (Ed.), Resilience for today: Gaining strength from adversity (pp. 141-160). Westport, CT: Praeger Publishers.

[20] Lee, J. H., Nam, S. K., Kim, A., Kim, B., Lee, M. Y., \& Lee, S. M. 2013. Resilience: A Meta-Analytic Approach. Journal of Counseling and Development : Journal of Counseling and Development,Volume 91 Issue 3, pp 269-274 Retrieved from http://www.questia.com

[21] Luthan F, Youssef MC, Avolio BJ, 2007. Psychological Capital: Developing the Human Competitive Edge, Oxford University Press, Inc. New York.

[22] Luthans, F. 2002a. The need for and meaning of positive organizational behaviour. Journal of Organizational Behaviour, Volume 23:pp 695-706. Retrieved from http://doi: 10.1002/job.165 
[23] Luthans, F.2000b.Positive Organisational Behaviour: Developing and Management Psychological strengths. Academy of Management Executive,pp 57-72.

[24] Luthans,F., and Youssef,C.M.2007a.Positive Organisational Behaviour in the Workplace:The Impact of Hope,Optimism, andResilience.Journal of Management, Volume 33 Issue 5,pp.774-800.

[25] Luthans,F., and Youssef,C.M.2007b. Emerging Positive Organisational Behaviour.University of Nebraska,Lincon:Leadership Institute faculty publication.Retrieved from http://digital commons.unl.edu/leadershipfacpub/8.

[26] Luthans,F.,Avolio,B.J.,AveyJ.B.,and Norman,S.M.2007.Positive Psychological Capital:Measurement and Relationship with Performance and satisfaction. University of Nebraska,Lincon:Leadership Institute faculty publication.Retrieved from http://digital commons.unl.edu/leadershipfacpub/11.

[27] Luthar, S. S., Cicchetti, D. and Becker, B. 2000. The Construct of Resilience: A Critical Evaluation and Guidelines for Future Work. Child Development,Volume71, pp 543-562. http://doi: 10.1111/1467-8624.00164

[28] Maddi, S. R.,and Deborah M. K.2005. Resilience at work: how to succeed no matter what life throws at you.NewYork:AMACOM.

[29] Masten, A., and Tellegen, A., 2012.Resilience in developmental psychopathology: Contributions of the Project Competence Longitudinal Study, Development and Psychopathology (Cambridge University Press)Volume 24, pp345-361.

[30] Masten, A.S., Best, K.M., Garmezy, N .1990. Resilience and development: Contributions from the study of children who overcome adversity. Development and Psychopathology Volume 2,pp 425-444.

[31] Newman, R.2003.Ch. 9.In The Wake Of Disaster:Building The Resilience InitiativeOfApa's Public Education Campaign.pp211240.FromGrotberg, E. H. (Ed.). (2003). Resilience for Today: Gaining Strength from Adversity. Westport, CT: Praeger. Retrieved from http://www.questia.com

[32] Ozbay F, Douglas C. J, Dimoulas E,Charney D and Southwick S, 2007. Social Support and Resilience to Stress, Psychiatry (Edgmont). 2007 May; Volume 4 Issue5, pp 35-40.

[33] Patterson, J.L.,Goens,G.A., and Reed,D.E.2009.Resilient leadership for Turbulent Times:A Guide to Thriving in the Face of Adversity. Maryland,USA:Rowman and Littlefield Education.

[34] Richardson, G. E.2002. The metatheory of resilience and resiliency. Journal of Clinical Psychology, Volume 58, pp 307-321.

[35] Seligman, M.E.P., and Csikszentmihalyi, M. 2000. Positive Psychology:AnIntroduction.American Psychologist Volume 55 No. 1 ,pp 5-14.

[36] Stine-Morrow, E. A. L., \& Chui, H. 2012. Cognitive resilience in adulthood. In J. B. Hayslip\& G. C. Smith (Eds.), Annual Review of Gerontology and Geriatrics (Vol 32, pp93-114). New York: Springer.

[37] Sharksnas, B.L.2002.The Relationship between Resilience and Job Satisfaction in Mental Health Care Workers.Ph.D. in Human Development. Retrieved from http://www.peaklearning.com/documents/PEAK GRI sharksnas.pdf

[38] Szanton, S. L., Gill, J. M., \& Thorpe, R. J. 2010. The Society-to-Cells Model of Resilience in Older Adults. Annual Review of Gerontology \& Geriatrics,Volume 30 Issue 1, pp 5-35. Retrieved from http://www.questia.com

[39] Thomas, D. 2011. Reaching resilience: Research made readable /2011/04/08/wave-one-resilient-qualities/Retrieved from https://denisannthomas.wordpress.com.

[40] Tugade, M.M. and Fredrickson, B.L.2004. Resilient Individuals Use Positive Emotions to Bounce Back From Negative Emotional Experiences.Journal of Personal and Social Psychology 86(2): 320-333.

[41] Wang, M. C., Haertel, G. D., \& Walberg, H. J. 1994. Educational resilience in inner cities. In M. C. Wang \& E. W. Gordon (Eds.), Educational resilience in inner-city America: Challenges and prospects (pp. 45-72). Hillsdale, NJ: Erlbaum.

[43] Werner, E. E. \& Smith, R. S. 1977. Kauai’s children come of age. Honolulu: University Press of Hawaii.

[44] Werner, E. E. \& Smith, R. S. 1982. Vulnerable but invincible: A longitudinal study of resilient children and youth. New York: McGraw-Hill Book Co.

[45] Werner, E. E. \& Smith, R. S. 1992. Overcoming the odds: High risk children from birth to adulthood. Ithaca, NY: Cornell University Press.

[46] Werner, E. E. \& Smith, R. S. 2001. Journeys from childhood to midlife: Risk, resilience, and recovery. Ithaca, NY: Cornell University Press.

[47] Werner, E. E., Bierman, J. M. \& French, F. E. 1971. The children of Kauai: A longitudinal study from the prenatal period to age ten. Honolulu: University of Hawaii Press.

Whitbeck, L., Hoyt, D., Stubben, J., \&LaFromboise, T. 2001. Traditional culture and academic success among American Indian children in the Upper Midwest. Journal of American Indian Education, Volume 40,pp 48-60. 